\title{
Peach Tree Response to Single and Combined Regulated Deficit Irrigation Regimes under Shallow Soils
}

\author{
Joan Girona, Mercè Mata, Amadeu Arbonès, Simó Alegre, Josep Rufat, and Jordi Marsal \\ Institut de Recerca i Tecnologia Agroalimentàries, Àrea de Tecnologia Frutícola, Centre UdL-IRTA. \\ Rovira Roure, 177, 25198 Lleida, Spain
}

AdDitional InDEX wORDS. Prunus persica, bloom return, fruit growth, vegetative growth, water stress, plant water potential

\begin{abstract}
Productive and vegetative tree responses were analyzed during 3 consecutive years in peach [Prunus persica (L.) Batsch cv. Sudanell] plots subjected to three regulated deficit irrigation (RDI) strategies plus a control irrigation treatment. A postharvest RDI treatment (RDI-P) was irrigated at 0.35 of control after harvest. A Stage II RDI treatment (RDI-SII) was irrigated at 0.5 of control during the lag phase of the fruit growth curve. The third treatment (RDI-SII-P) applied RDI during Stage II at 0.5 of control and postharvest at 0.35 of control. The control treatment, like RDI-P and RDI-SII-P when not receiving RDI, was irrigated at $100 \%$ of a water budget irrigation scheduling in 1994 and 1996 , full crop years, and $80 \%$ of the budget in 1995, an off year with a very small crop. A carry-over effect of deficit irrigation was highly significant in all parameters measured during the third year of the experiment. The general effect of water stress during Stage II did not affect return bloom and fruit set, whereas water stress during postharvest apparently reduced both parameters. As a consequence, fruit counts and fruit load manifested marked differences between treatments, which were also correlated to changes in fruit size. The RDI-II, which had the highest fruit yield, also had the smallest fruit size, whereas RDI-P manifested the lowest yield and largest fruit size. Vegetative growth (shoot elongation and trunk cross sectional area) was significantly reduced during the first 2 years of the experiment in accordance with the amount of the irrigation reduction. However, in 1996 growth was strongly governed by fruit load. The use of RDI-SII-P represented an intermediate cropping effect between the opposite bearing behavior of RDI-SII and RDI-P, while not expecting distinctive fruit yield or size reductions and offering remarkable water savings of $22 \%$ of the control applied water.
\end{abstract}

The introduction of regulated deficit irrigation (RDI) during the early 1980s (Chalmers et al., 1981; Mitchell et al., 1984) encouraged new research on the water requirements in fruit trees. The concept was to control excessive vegetative growth by means of water stress. However the question of tree seasonal sensitivity to water deficits (DeJong, 1995) remained largely unresolved. Later studies were conducted on other tree species (Alegre et al., 2002; Caspari et al., 1994; Domingo et al., 1996; Goldhamer, 1999; Gonzalez-Altozano and Castel, 1999). Although the RDI benefits were primarily focused on the reduction of vegetative growth and enhancement of fruit growth (Chalmers et al., 1981, Li et al., 1989), other advantages have also been described, i.e., a general tendency to improve fruit taste and quality (Fereres and Goldhamer, 1990), and an improvement of postharvest shelf life (Crisosto et al., 1994). Additionally, RDI has been shown to change flowering behavior the year following its application, both in Prunus (Girona et al., 1997; Goldhamer and Viveros, 2000; Johnson et al., 1992; Lampinen et al. 1995; Li et al., 1989) and in Pyrus (Caspari et al., 1994; Marsal et al., 2002). In all of these studies phenological sensitivity to water stress is reported. Although the first RDI work in peach and pear trees showed clear benefits (Chalmers et al., 1981; Mitchell et al., 1984), and subsequent studies have demonstrated the usefulness of this technique, not all situations seem optimal for the RDI. Such would be the case with peach orchards in some areas of California with deep sandy soils (Girona, 1989), or when irrigating with saline water (Boland et al., 1993) or in special container growth conditions (Marsal et al., 2000).

Due to the increasing limitation of water availability for irriga-

Received for publication 15 Jan. 2002. Accepted for publication 28 Jan. 2003. This research was partially supported by the Spanish National Research Institute for Agriculture (INIA SC-93-059-C6). The revision of the manuscript by T.M. DeJong is gratefully acknowledged. The authors thank the owner of the plot where the experiment was carried out, Mariano Morell, for being so comprehensive, and Jaime Garcia, Eli Ibarz, Albert Vall-1lebrera, and Alex Mata for their participation and hard work. tion of horticultural crops in large areas of the world, there is an increasing risk of losing irrigated land. Reducing applied water during certain periods of the year could improve water use efficiency and conservation. Under these new conditions, the focus would not only be to achieve productions above average or control excessive vegetative growth but to reduce water use even at the possible risk of a slight reduction in production.

Although previous studies analyzed the effect of water deficit on fruit growth (Chalmers et al., 1981; Girona, 1989; Goldhamer et al., 1999; Li et al., 1989; Mitchell et al., 1984), the results were not conclusive, probably, because of different experimental conditions (cultivar, soil, plant density, weather, etc.). Soil depth and soil water holding capacity have been reported as interacting factors in the success of RDI (Behboudian and Mills, 1997). According to those studies, two different periods of the annual cycle seem the most suitable for reducing irrigation: Stage II of fruit growth development (Chalmers et al., 1981; Li et al., 1989), and postharvest (Johnson et al., 1992).

The objective of the present work is to analyze the seasonal sensitivity of peach trees to water stress in Stage II and postharvest periods, in a single or a combined stress period, in trees cultivated in a shallow soil. The interest is mainly to evaluate the effects of water stress on fruit and vegetative growth, fruit load, phenological behavior, and their interactions.

\section{Material and Methods}

EXPERIMENTAL ORCHARD. The experiment was conducted over 3 years (1994-96) in a 0.7-ha peach plot located in a commercial orchard in the Lleida province of Spain $\left(41.38{ }^{\circ} \mathrm{N}, 0.35^{\circ} \mathrm{E}\right)$. The soil is Typic Xerothent with an average of $50-\mathrm{cm}$ loam soil profile. The average rainfall during the irrigation period of the 3year experiment was $174 \mathrm{~mm}$. The first experimental year (1994) was particularly dry and there was almost no precipitation from mid-May until mid-September, whereas the following 2 years 
were slightly wetter and accumulated around $20 \mathrm{~mm}$ during the same period. The average maximum daily temperature during summer was $\approx 33{ }^{\circ} \mathrm{C}$ whereas minimum relative humidity was usually $\approx 30 \%$. An automated drip irrigation system with four compensating emitters $\left(4 \mathrm{~L} \cdot \mathrm{h}^{-1}\right)$ per tree was used with water meters in each replication to monitor applied irrigation water. Wetted surface soil was $\approx 35 \%$ of the shaded area. The plot was managed according to commercial practices with a mowed cover crop strip between rows. The trees were heavily cropped in 1994 and 1996 with more than five fruit $/ \mathrm{cm}^{2}$ on a trunk cross section area basis (fruit load). In 1995, an April freeze eliminated most of the crop (fruit load $<0.4$ fruit $/ \mathrm{cm}^{2}$ ). In 1994 and 1996 the trees were thinned in late May to a commercially acceptable level. Fruit was harvested between 3 to 15 August, in three picks at commercial maturity.

EXPERIMENTAL DESIGN. A total of 352 five-year old trees on peach seedling rootstock and 'Sudanell' scion (medium-late maturing peach) were used. Tree spacing was $5 \times 3 \mathrm{~m}$ and the trees were pruned to a vase system. The plot was oriented north-south. A randomized complete-block design with four blocks was originally established. Each block consisted of three adjacent tree rows with 10 trees in each row. The center two trees of the middle row were used for physiological measurements, whereas the six center trees of the middle row were used to measure vegetative and production parameters.

IRRIGATION TREATMENTS. Four irrigation treatments were applied: control (C), and three RDI regimes: postharvest RDI treatment (RDIP), Stage II fruit development RDI regime (RDI-SII) and a combined Stage II plus postharvest RDI treatment (RDI-SII-P). In order to achieve even higher water savings in the combined RDI treatment (RDI-SII-P), deficit irrigation during Stage II was extended in the former for 1 week longer than in RDI-SII. The control treatment was fully irrigated using a water budget approach by subtracting effective rainfall $\left(\right.$ (rain $\left._{\mathrm{ef}}\right)$ from crop evapotranspration $(\mathrm{ETc})$. ETc was calculated from a modified Penman-determined reference crop water use (ETo) (Doorenbos and Pruitt, 1977) with estimated crop coefficients (Kc) adapted from Goldhamer and Snyder (1989) (ETc $=\mathrm{ETo} \cdot \mathrm{Kc})$ and modified in situ based on plant water status. Initial $\mathrm{Kc}_{1}$ (rapid growth) was $0.25, \mathrm{Kc}_{2}$ (midseason) $=1$ (with a maximum $\mathrm{Kc}_{2}=1.05$ during rapid fruit growth) and $\mathrm{Kc}_{3}$ (late season) $=0.55$. Irrigation began at flowering (first week of March), trees leafed out on 20 Mar., full leaf growth was completed by 15 June, harvest was finished by 15 Aug., and the end of the irrigation season was on 5 Nov. The RDI-SII and RDI-SII-P trees were irrigated at 50\% of control during fruit growth Stage II; RDI-P and RDI-SII-P were irrigated at $35 \%$ of control during postharvest. Since defruited trees often consume less water than fully cropped trees (Chalmers et al., 1983) the control in the 1995 low crop year was irrigated at $80 \%$ of the water budget throughout the season.

Meteorological MEASUREMENTS. Meteorological data for the Penman equation were collected at the nearest automated weather station (EMECA, $19 \mathrm{~km}$ from the study plot). This station is part of the Catalonian network of weather stations (Generalitat de Catalunya, 1994). Air temperature, relative humidity, photosynthetic active radiation, rainfall and soil temperature were also recorded at a meteorological station situated in the plot itself.

Plant Water Potential Measurements. Leaf water potential at predawn $\left(\Psi_{\mathrm{pd}}\right)$ and at midday $\left(\Psi_{1}\right)(1200 \mathrm{HR}$ local time $)$ was measured weekly in 1994 using four leaves (two per tree) per experimental plot using the pressure chamber (model 3005; Soil Moisture Equipment Corp., Santa Barbara, Calif.) technique (Scholander et al., 1965), and taking the precautions suggested by Turner and
Long (1980). Sample frequency was lower in 1995 and 1996 with 2 sampled days during Stage II and 4 during Stage III. Sampled leaves were fully mature, well exposed and dew-free. All readings were taken on sunny days.

VEGETATIVE GROWTH MEASUREMENTS. Trunk circumference measurements were taken monthly during the nondormant period to evaluate the annual increases in trunk cross sectional area (TCSA) by using a metallic tape tool designed by K.A. Shackel (personal communication). Shoot elongation was measured on two randomly tagged nonterminal shoots per tree ( 12 shoots per experimental plot) and determined at intervals of 2 to 3 weeks, depending on the vegetative activity at the time. During the last year of the study (1996), intercepted photosynthetic photon flux density (IPPFD) was determined using an Accupar Linear PAR Ceptometer (Decagon Devices, Inc., Pullman, Wash.). Thirty measurements were taken just above the soil surface for each experimental plot, which corresponded to a grid with measurements made at 0,1 and $2 \mathrm{~m}$ from the trunk moving across the tree row and on both sides. Pruning weights were determined immediately after hand pruning during the dormant season of each year, following the application of irrigation treatments.

Flowering, FRUIT GROWTH, AND YIELD MEASUREMENTS. Fruit set and fruit load after thinning were determined from flower and fruit counts on two secondary branches per tree from bloom to harvest. These branches were facing opposite directions and their basal diameter was between 3 and $4 \mathrm{~cm}$. Fruit set was calculated as the percentage of those flowers that continued growing actively 1 (FSA1M) or 2 (FSA2M) months after full bloom as normal fruit. Fruit load after thinning was determined as the number of fruit per shoot at that time. Thinning was normally carried out 2.5 months after full bloom. In 1995 and 1996, four random 1-year-old horizontal fruiting shoots per tree were sampled 2 weeks before bloom. Shoot length, the number of flower buds, and the number of nodes per shoot were determined from them and two parameters were calculated: the number of buds per node and flower density as the total number of flowers per unit of shoot length.

Fruit growth estimates were determined using two random fruit per tree (12 per experimental plot) sampled weekly from early April to harvest and brought to the laboratory for the determination of fruit fresh and dry weight. In 1995, fruit were sampled less often and sample size was reduced to seven fruit per treatment. Dry weight was obtained after drying the sample at $70{ }^{\circ} \mathrm{C}$ to a constant weight. Fruit relative dry matter (RDM) was calculated as $100 \cdot($ dry weight/fresh weight). On the day before harvest in 1995 and 1996 preharvest fruit drop was determined by counting the fruit laying on the ground. At harvest, fruit number and total fruit fresh mass were determined for each tree during three consecutive pickings.

Table 1. Water balance components for the different experiment years and growth periods (reference evapotranspiration, ETo, and rainfall).

\begin{tabular}{lcccc}
\hline Year & Stage I & Stage II & Stage III & Postharvest \\
\hline ETo (mm/period) & & & & \\
1994 & 216 & 115 & 295 & 200 \\
1995 & 273 & 101 & 229 & 206 \\
1996 & 346 & 113 & 203 & 195 \\
$\begin{array}{l}\text { Rainfall (mm/period) } \\
1994\end{array}$ & & & \\
1995 & 46 & 10 & 10 & $213(9 / 13)^{\mathrm{z}}$ \\
1996 & 26 & 9 & 19 & $58(9 / 09)$ \\
\hline
\end{tabular}

z Period free of rainfall from harvest until indicated date (month/day). 
Table 2. Applied water and percentages from control, per year and averages for the 3 year experiment for each irrigation treatment.

\begin{tabular}{|c|c|c|c|c|c|c|c|c|}
\hline \multirow[b]{2}{*}{ Treatment } & \multicolumn{2}{|c|}{1994} & \multicolumn{2}{|c|}{1995} & \multicolumn{2}{|c|}{1996} & \multicolumn{2}{|c|}{ Mean 3 years } \\
\hline & $\mathrm{mm}$ & $\%$ & $\mathrm{~mm}$ & $\%$ & $\mathrm{~mm}$ & $\%$ & $\mathrm{~mm}$ & $\%$ \\
\hline Control & 764 & 100 & 635 & 100 & 628 & 100 & 676 & 100 \\
\hline RDI-SII & 725 & 95 & 551 & 87 & 604 & 96 & 627 & 93 \\
\hline RDI-SII-P & 618 & 81 & 467 & 73 & 516 & 78 & 530 & 77 \\
\hline
\end{tabular}

Mean truit weight was estımated by divıdıng total tresh weight over total fruit number per tree. A subsample of $25 \%$ of total fruit weight per experimental plot was used to determine fruit size distribution based on fruit diameter categories of $5 \mathrm{~mm}$.

Statistical Analysis. Data were initially analyzed together as a repeated measurements analysis. Analysis of variance was also performed separately each year for yield components and vegetative parameters according to a complete randomized block model with each block being a replication unit. Each block data was the contribution of six experimental trees. Mean separation was done by using Duncan's multiple range test at 0.05 level of significance. Statistical analysis was performed using the PROC GLM (SAS Institute Inc., 1988).

\section{Results}

In general, the amount of water applied was greater in 1994 than in either of the other 2 years in accordance with more severe weather conditions during times when evaporimetric demand was high (Stage III) (Tables 1 and 2). The quantity of applied water during the 3-year experiment varied slightly from year to year. An average for the 3-year period under control conditions was 676 $\mathrm{mm} \cdot$ year $^{-1}$ (Table 2). The total amount of water that could be saved with RDI scheduling was dependent on the periods when deficit was applied; with RDI-SII treatment, water savings with respect to control were on average $7 \%$, whereas in the RDI-P strategy, the estimates reached up to $16 \%$ (Table 2). The maximum rates, however, were achieved with the RDI-SII-P treatment with an average of $23 \%$ (Table 2).
Such restrictions in irrigation induced signiticant ditferences in tree water potential between irrigation treatments during the deficit periods. The greatest differences were found in RDI-SII-P for both $\Psi_{\mathrm{pd}}$ and $\Psi_{1,}$ and the lowest values were reached during the full crop years (1994 and 1996) at the end of their deficit irrigation periods with treatment averages in $\Psi_{1}$ slightly lower than $-2.0 \mathrm{MPa}$ (Table 3). In the RDI-SII, the lowest average values in $\Psi_{1}(-1.85$ $\mathrm{MPa}$ ) were observed 1 week before those in RDI-SII-P because of differences in deficit irrigation scheduling (Table 3). During the postharvest period, water potential values were also markedly decreased in RDI trees. The estimates of $\Psi_{1}$ were significantly lower in RDP-SII-P and RDI-P than those of fully irrigated treatments at that time (control and RDI-SII); in this case, the lowest values measured for 1994 (-2.66 MPa for the RDI-P) were even more negative than those of Stage II (Table 3). The observed treatment changes in $\Psi_{1}$ were, in general, consistent with what was manifested from $\Psi_{\text {pd }}$ (Table 3).

Secondary trunk growth was significantly inhibited in the RDI during 1994 and 1995 in accordance with the amount of restriction in applied water (Fig. 1). In 1994 treatment differences were not statistically significant, but during 1995 RDI-SII-P trunk growth increments were significantly lower than RDI-P and the control (Fig. 1). Likewise, neither RDI-SII nor RDI-Punderwent significant reduction in growth with respect to the control (Fig. 1). However, these tendencies were substantially modified during 1996. Trees from control and RDI-SII-P followed identical trends, whereas the trunk growth of RDI-SII was substantially inhibited, and RDI-P, on the contrary, had the highest growth rates (Fig. 1). On the 3year experiment basis, RDI treatments with deficit during Stage

Table 3. Average $\Psi_{\mathrm{pd}}$ and $\Psi_{1}$ in different stages of fruit growth development and irrigation treatments. The average values for Stage II and postharvest corresponds to the most stressed day for each deficit irrigated period (last day of the period). The values for Stage III corresponds to the average values measured throughout the period.

\begin{tabular}{|c|c|c|c|c|c|c|c|}
\hline \multirow[b]{2}{*}{ Stage } & \multirow[b]{2}{*}{ Treatment } & \multicolumn{3}{|c|}{$\Psi_{\mathrm{pd}}(-\mathrm{MPa})$} & \multicolumn{3}{|c|}{$\Psi_{1}(-\mathrm{MPa})$} \\
\hline & & 1994 & 1995 & 1996 & 1994 & 1995 & 1996 \\
\hline \multirow[t]{4}{*}{ Stage II } & Control & $0.36 \mathrm{a}^{\mathrm{Z}}$ & $0.29 \mathrm{a}$ & $0.42 \mathrm{a}$ & $1.48 \mathrm{a}$ & $1.35 \mathrm{a}$ & $1.25 \mathrm{a}$ \\
\hline & RDI-SII & $0.44 \mathrm{~b}$ & $0.86 \mathrm{~b}$ & $0.59 \mathrm{~b}$ & $1.77 \mathrm{~b}$ & $1.85 \mathrm{~b}$ & $1.62 \mathrm{bc}$ \\
\hline & RDI-SII-P & $0.56 \mathrm{c}$ & $0.87 \mathrm{~b}$ & $0.86 \mathrm{c}$ & $2.18 \mathrm{c}$ & $1.75 \mathrm{~b}$ & $1.86 \mathrm{c}$ \\
\hline & ANOVA $^{(y)}$ & $* *$ & $* * *$ & $* * *$ & $* * *$ & $* * *$ & $*$ \\
\hline \multirow{3}{*}{ Stage III } & Control & 0.42 & 0.51 & 0.33 & 1.80 & 1.61 & 1.24 \\
\hline & RDI-SII-P & 0.36 & 0.58 & 0.42 & 1.72 & 1.62 & 1.33 \\
\hline & ANOVA & NS & NS & NS & NS & NS & NS \\
\hline \multirow[t]{3}{*}{ Postharvest } & Control & $0.46 \mathrm{a}$ & --- & --- & $1.73 \mathrm{a}$ & --- & --- \\
\hline & RDI-SII & $0.55 \mathrm{a}$ & --- & --- & $1.97 \mathrm{ab}$ & --- & --- \\
\hline & RDI-P & $1.03 \mathrm{~b}$ & --- & --- & $2.66 \mathrm{c}$ & --- & --- \\
\hline
\end{tabular}

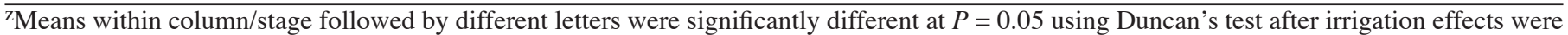
shown to be significant with ANOVA test with $P<0.05$.

Ns, $, * *, * * *$ Nonsignificant or significant at $P<0.05,0.01$, or 0.001 , respectively, by ANOVA with complete randomized blocks. 


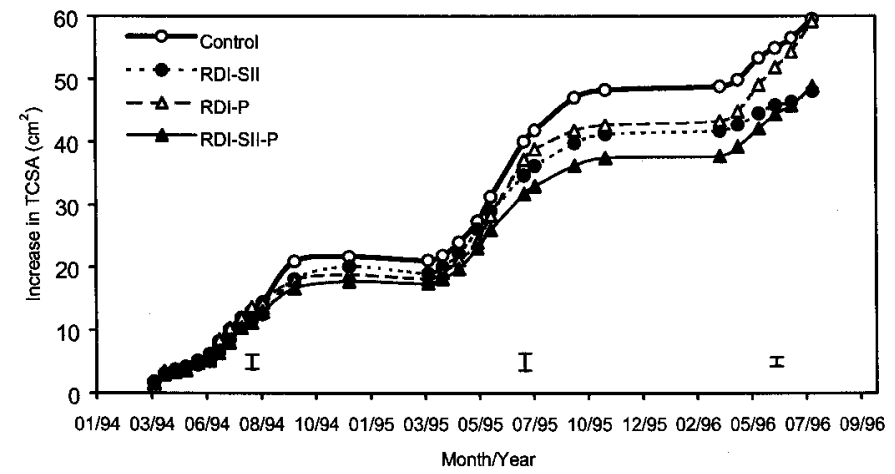

\begin{tabular}{|lccccc|}
\hline & & & & & \\
Treatment & Year 94 & Year 95 & Year 96 & Accum.94-95 & Accum.94-96 \\
\hline Control & 21.6 & $26.6 \mathrm{a}$ & $11.2 \mathrm{~b}$ & $48.8 \mathrm{a}$ & $59.5 \mathrm{a}$ \\
RDI-SII & 20.1 & $21.1 \mathrm{bc}$ & $6.8 \mathrm{c}$ & $41.6 \mathrm{~b}$ & $48.1 \mathrm{~b}$ \\
RDI-P & 18.8 & $23.8 \mathrm{ba}$ & $16.5 \mathrm{a}$ & $43.3 \mathrm{ab}$ & $59.1 \mathrm{a}$ \\
RDI-SII-P & 17.8 & $19.7 \mathrm{c}$ & $11.3 \mathrm{~b}$ & $37.7 \mathrm{~b}$ & $48.8 \mathrm{~b}$ \\
ANOVA & NS & $* *$ & $* *$ & $*$ & $* *$ \\
\hline
\end{tabular}

Fig. 1. Seasonal patterns of the increase in trunk cross sectional area (TCSA) from the beginning of the experiment, and the statistical significance of the yearly accumulated growth (below in table; ss, ,**,****Nonsignificant or significant at $P<$ $0.05,0.01$, or 0.001 , respectively, by ANOVA with complete randomized blocks and different letters showing significance at $P=0.05$ using Duncan's test). Each error bar represents the yearly pooled standard error, and each symbol is the treatment average for 24 tree measurements (six trees in each one of the four replications). Open circles with a coarse line represent control, closed circles and dotted lines RDI-SII, open triangles and a dashed line RDI-P, and closed triangles and a thin line RDI-SII-P.
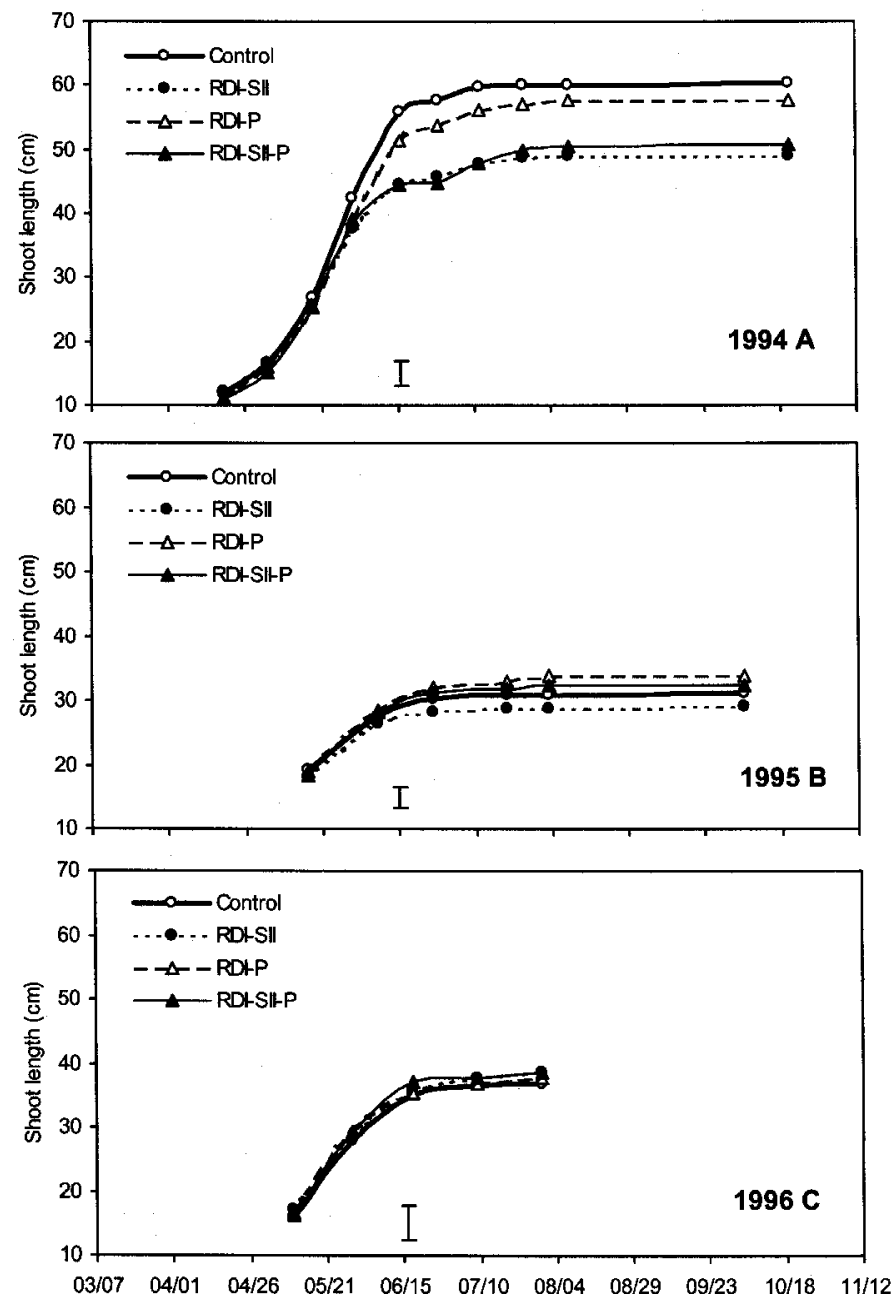

II manifested the lowest growth rates, whereas those of RDI-P were not significantly different from the control (Fig. 1). Shoot elongation during 1994 was clearly reduced in those treatments that underwent water deficits during Stage II (RDI-SII and RDISII-P) (Fig. 2A). This was coincident with the shoot enlargement phase. However, over the following 2 years a clear pattern of shoot growth differentiation between treatments was not observed (Fig. $2 \mathrm{~B}$ and $\mathrm{C}$ ).

There were no clear differences in patterns of fruit dry and fresh weight between treatments in 1994 (Fig. 3A and B). There was only a slight tendency for diminished fresh fruit values in RDI-SII and RDI-SII-P at the end of Stage II (Fig. 3A). However, this was not related to changes in real growth, but to passive fruit dehydration because relative dry weight (RDM) was higher in the above-mentioned treatments than in control or RDI-P (Fig. 3C). Such differences in RDM were more marked at the end of Stage II and did not disappear immediately after the relief of water stress (Fig. 3 C). In fact, it took $\approx 3$ weeks of full irrigation during Stage III to equalize RDM values between irrigation treatments (Fig. 3C). In 1995, RDM treatment differences during Stage II were even more accentuated than in 1994 (Fig. 3F). Nevertheless, in 1995, the typical double sigmoid fruit development curve provoked by the lag Stage II phase was not evident (Fig. 3D and E). On the other hand, differences between treatments in 1996 were observed as soon as Stage II was initiated (Fig. 3G and H). RDI-P and RDI-SII-P tended to manifest higher values of fruit fresh and dry weight at that moment, but later on, during Stage III, the pattern was even clearer, with RDI-P fruit (fresh and dry weights) larger and RDISII smaller than control (Fig. $3 \mathrm{G}$ and $\mathrm{H}$ ).

Irrigation treatment effects $(\mathrm{T})$ on fruit yield evaluated on the grounds of repeated measurements reflected significant differences in fruit count and load as well as in total yield (Table 4). However, the effect of $\mathrm{T}$ on mean fresh fruit weight was not significant but the year $\times$ treatment $(\mathrm{Y} \times \mathrm{T})$ was, as in the other fruit yield components (Table 4). The significance of the $\mathrm{Y} \times \mathrm{T}$ effect stimulated us to evaluate the irrigation effects separately for each year. In 1994, and despite the fact that significant differences in mean fruit fresh weight were not observed, fruit counts in the RDI-SII-P were apparently higher at harvest than RDI-P or control (Table 5). Control trees and RDI-P treatments had the lowest fruit load and yield values in 1994. RDI-SII was intermediate, without significant differences from the other treatments (Table 5). In 1995, the frost year, the productive load was reduced 10 -fold with respect to the full crop year 1994, and despite this, significant differences in fruit yield were still found (Table 5). RDI-SII manifested a significantly higher yield than RDI-P (Table 5). However, neither average fruit fresh mass nor fruit count showed significant treatment differences (Table 5). In the following year, 1996, differences in fruit yield between RDI-SII and RDI-P were maximized, whereas estimates in all the other treatments were significantly different, with the exception of control and RDI-SII-P (Table 5). In general, fruit yield in 1996 was superior to that in 1994 (Table 5). All the other components of fruit yield (mean fruit fresh weight and count) and fruit load were highly significant that year. The fruit fresh weight values were ordered from highest to lowest treatment averages in the following sequence: RDI-P > RDI-SII-P > control > RDI-SII,

Fig. 2. Seasonal patterns of elongative shoot during 1994 (A), 1995 (B) and 1996 (C). Each error bar represents the yearly pooled standard error and each symbol is the treatment average for 24 trees with two measurements per tree. Open circles with a coarse line represent control, closed circles and dotted lines RDI-SII, open triangles and a dashed line RDI-P, and closed triangles and a thin line RDI-SII-P. 
which in turn was the opposite of that manifested by fruit count (Table 5). Since there was no treatment effect on fruit size when fruit load was corrected by means of a covariance analysis (data not shown), it is likely that changes in fruit size were triggered by fruit competition.

The effects of RDI treatments on flowering and fruit set (FSA1M) behavior were not found to be significant during the first 2 years of the experiment (Table 6). In the third year, however, noticeable differences were found in flower density and fruit set. Both parameters were highest in the control and RDI-SII treatments, whereas the postharvest deficit irrigated treatments exhibited the lowest values, especially in fruit set for RDI-P(Table 6). These differences were so important that manual fruit thinning was not enough to eliminate fruit per shoot count differences between treatments. RDI-SII had the highest counts and RDI-P the lowest, whereas differences between control and RDI-SII-P were not significant (Table 6). On the other hand, the cultivar used in this experiment ('Sudanell') manifested a susceptibility to fruit splitting before harvest. Fruit drop during prematuration in 1996 was lowest in the RDI-SII trees (Table 6).

There were no significant differences in pruning weights during the first 2 years of the experiment but in 1996 pruning weights were highest in RDI-P (Table 6). This pattern was consistent with that shown by crop intercepted radiation (IPPFD) (Table 7). The RDI-P trees intercepted statistically higher incoming radiation $(78 \%)$ than those of RDI-SII (70\%) (Table 7).

\section{Discussion}

It is commonly accepted that during pit hardening (Stage II) peach fruit growth is not very sensitive to water stress (Chalmers et al., 1981; Li et al., 1989). In this study, the effects of the different irrigation treatments on peach fruit growth were negligible during the first year of the experiment. Although Stage II deficit irrigated fruit manifested dehydration (RDM, Fig. 3C), further growth rates in fresh and dry weight were not affected in any of the RDI treatments (Fig. 3A and B). The largest treatment differences in fruit $\mathrm{RDM}$ at the end of Stage II were coincidental with the lowest estimates in $\Psi_{1}(-2.18 \mathrm{MPa})$ (Table 3$)$. The RDI-SII-P/RDI-SII differences in RDM were also linked to a difference in water stress levels which were provoked by the 1-week gap when resuming full irrigation (Table 3). In other experiments, however, reductions in fresh weight were noticed during Stage III, because tree water stress was extended for several weeks, well into the sensitive growth
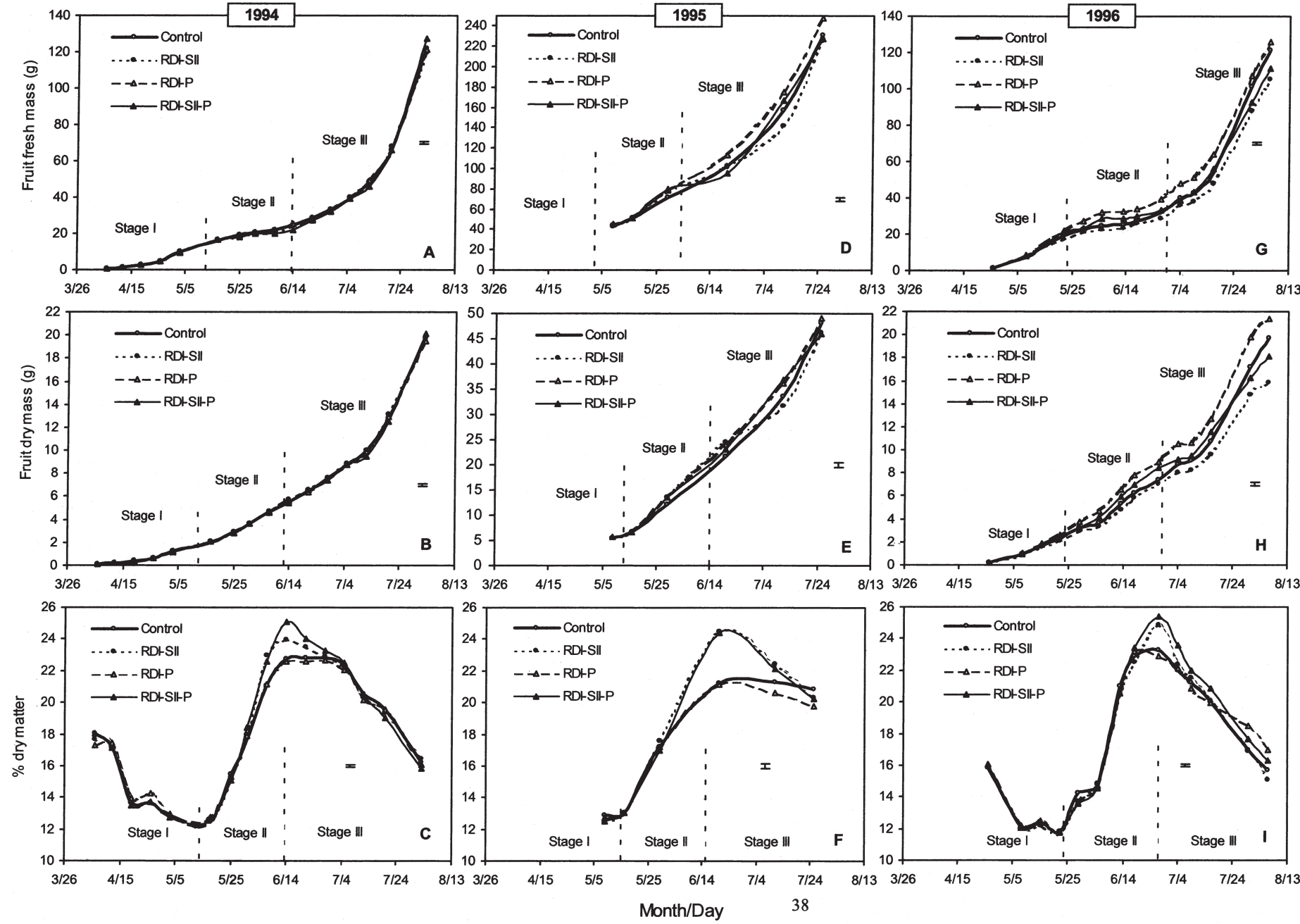

Fig. 3. Seasonal patterns of fruit fresh mass (A, D, G), fruit dry mass $(\mathbf{B}, \mathbf{E}, \mathbf{H})$, and relative dry matter $(\mathbf{C}, \mathbf{F}, \mathbf{I})$ for the experimental year $1994(\mathbf{A}, \mathbf{B}, \mathbf{C}), 1995$ (D, E, F) and 1996 (G, H, I). Scale in 1995 is enlarged in order to improve vision in 1994 and 1996. Each error bar represents the yearly pooled standard error and each symbol is the treatment average for 24 trees with two fruit sampled per tree (with the exception of 1995 when only seven fruit per treatment were used). Open circles with a coarse line represent control, closed circles and dotted lines RDI-SII, open triangles and a dashed line RDI-P, and closed triangles and a thin line RDI-SII-P. 
Table 4. Effects of irrigation treatments on fruit yield components by repeated measurements analysis of variance for the experimental period 1994-96. The error term for all the elements is the matrix SS and $\mathrm{CP}$.

\begin{tabular}{lccccc}
\hline & & \multicolumn{4}{c}{ Pr $>\mathrm{F}$} \\
\cline { 3 - 6 } & & $\begin{array}{c}\text { Fruit } \\
\text { fresh } \\
\text { Source }\end{array}$ & $\begin{array}{c}\text { Fruit } \\
\text { fresh } \\
\text { yield }\end{array}$ & $\begin{array}{c}\text { Fruit } \\
\text { wt }\end{array}$ & $\begin{array}{c}\text { Fruit } \\
\text { load }\end{array}$ \\
\hline $\begin{array}{l}\text { Between subjects effects } \\
\text { Treatment (T) }\end{array}$ & 3 & 0.0001 & 0.2638 & 0.0001 & 0.0001 \\
$\quad$ Block (B) & 3 & 0.0001 & 0.0372 & 0.0001 & 0.0001 \\
B $\times \mathrm{T}$ & 9 & 0.3359 & 0.3675 & 0.4135 & 0.3213 \\
Within subjects effects & & & & & \\
$\quad$ Year (Y) & 2 & 0.0001 & 0.0001 & 0.0001 & 0.0001 \\
$\quad \mathrm{Y} \times \mathrm{T}$ & 6 & 0.0001 & 0.0001 & 0.0001 & 0.0001 \\
\hline
\end{tabular}

phase (Girona, 1989; Girona et al., 1993). This was not the case under the conditions of this experiment, because in these shallow soils ( $0.50 \mathrm{~m}$ deep) water stress after Stage II was relieved in less than a week (Marsal and Girona, 1997). Such conditions facilitate the adequate timing of water stress application that is needed in an RDI strategy. Moreover, Boland et al. (2000) reported that an RDI technique can be more successful in shallow soils because the root restricted environment makes it easier to control excessive vegetative growth.

In 1994, it was unexpected that fruit counts were lower at harvest for the treatments that had not received any previous irrigation restriction (control and RDI-P; Table 5). It is unlikely that these lower fruit counts were due to inherent differences in the trees before the experiment, because the same treatment divergences were found for fruit load (Table 5). Similarly, variations in fruit set or thinning
Table 5. Effects of irrigation treatments on fruit fresh yield and weight, fruit load and fruit count for the experimental period 1994 to 1996.

\begin{tabular}{|c|c|c|c|c|}
\hline \multirow[b]{2}{*}{$\begin{array}{l}\text { Irrigation } \\
\text { treatment }\end{array}$} & \multicolumn{4}{|c|}{ Avg and probability } \\
\hline & $\begin{array}{c}\text { Fruit } \\
\text { fresh } \\
\text { yield } \\
(\mathrm{kg} / \text { tree })\end{array}$ & $\begin{array}{l}\text { Fruit } \\
\text { fresh } \\
\mathrm{wt} \\
(\mathrm{g})\end{array}$ & $\begin{array}{c}\text { Fruit } \\
\text { load } \\
\text { (no. fruit } / \mathrm{cm}^{2} \text { ) }\end{array}$ & $\begin{array}{c}\text { Fruit } \\
\text { count } \\
\text { (no./tree) }\end{array}$ \\
\hline \multicolumn{5}{|l|}{$\overline{1994}$} \\
\hline RDI-SII-P & $60.9 \mathrm{a}$ & 137.3 & $6.55 \mathrm{a}$ & $444 \mathrm{a}$ \\
\hline RDI-SII & $54.9 \mathrm{ab}$ & 131.5 & $5.84 \mathrm{ab}$ & $424 \mathrm{ab}$ \\
\hline Control & $51.8 \mathrm{~b}^{(\mathrm{z})}$ & 133.5 & $5.26 \mathrm{~b}$ & $391 \mathrm{~b}$ \\
\hline RDI-P & $50.0 \mathrm{~b}$ & 134.0 & $5.26 \mathrm{~b}$ & $375 \mathrm{~b}$ \\
\hline ANOVA(y) $^{(y)}$ & $* *$ & NS & $*$ & $*$ \\
\hline \multicolumn{5}{|l|}{1995} \\
\hline RDI-SII & $9.1 \mathrm{a}$ & 221.1 & 0.38 & 37 \\
\hline RDI-SII-P & $5.6 \mathrm{ab}$ & 214.7 & 0.28 & 29 \\
\hline Control & $4.6 \mathrm{ab}$ & 207.5 & 0.21 & 20 \\
\hline RDI-P & $4.7 \mathrm{~b}$ & 196.5 & 0.14 & 18 \\
\hline ANOVA & $*$ & NS & NS & NS \\
\hline \multicolumn{5}{|l|}{1996} \\
\hline RDI-SII & $111.4 \mathrm{a}$ & $149.5 \mathrm{~d}$ & $6.99 \mathrm{a}$ & $760 \mathrm{a}$ \\
\hline Control & $91.3 \mathrm{~b}$ & $168.6 \mathrm{c}$ & $5.47 \mathrm{~b}$ & $561 \mathrm{~b}$ \\
\hline RDI-SII-P & $83.7 \mathrm{~b}$ & $181.6 \mathrm{~b}$ & $5.20 \mathrm{~b}$ & $490 \mathrm{~b}$ \\
\hline RDI-P & $65.9 \mathrm{c}$ & $202.6 \mathrm{a}$ & $3.06 \mathrm{c}$ & $347 \mathrm{c}$ \\
\hline ANOVA & $* * *$ & $* * *$ & $* * *$ & $* * *$ \\
\hline
\end{tabular}

${ }^{2}$ Means within column/year followed by different letters were significantly different at $P=0.05$ using Duncan's test.

Ns, *******Nonsignificant or significant at $P<0.05,0.01$, or 0.001 , respectively, by ANOVA with complete randomized blocks.

Table 6. Effects of irrigation treatments on fruit set and preharvest drop through fruit growth cycle and pruning weight for the experimental period 1994 to 1996

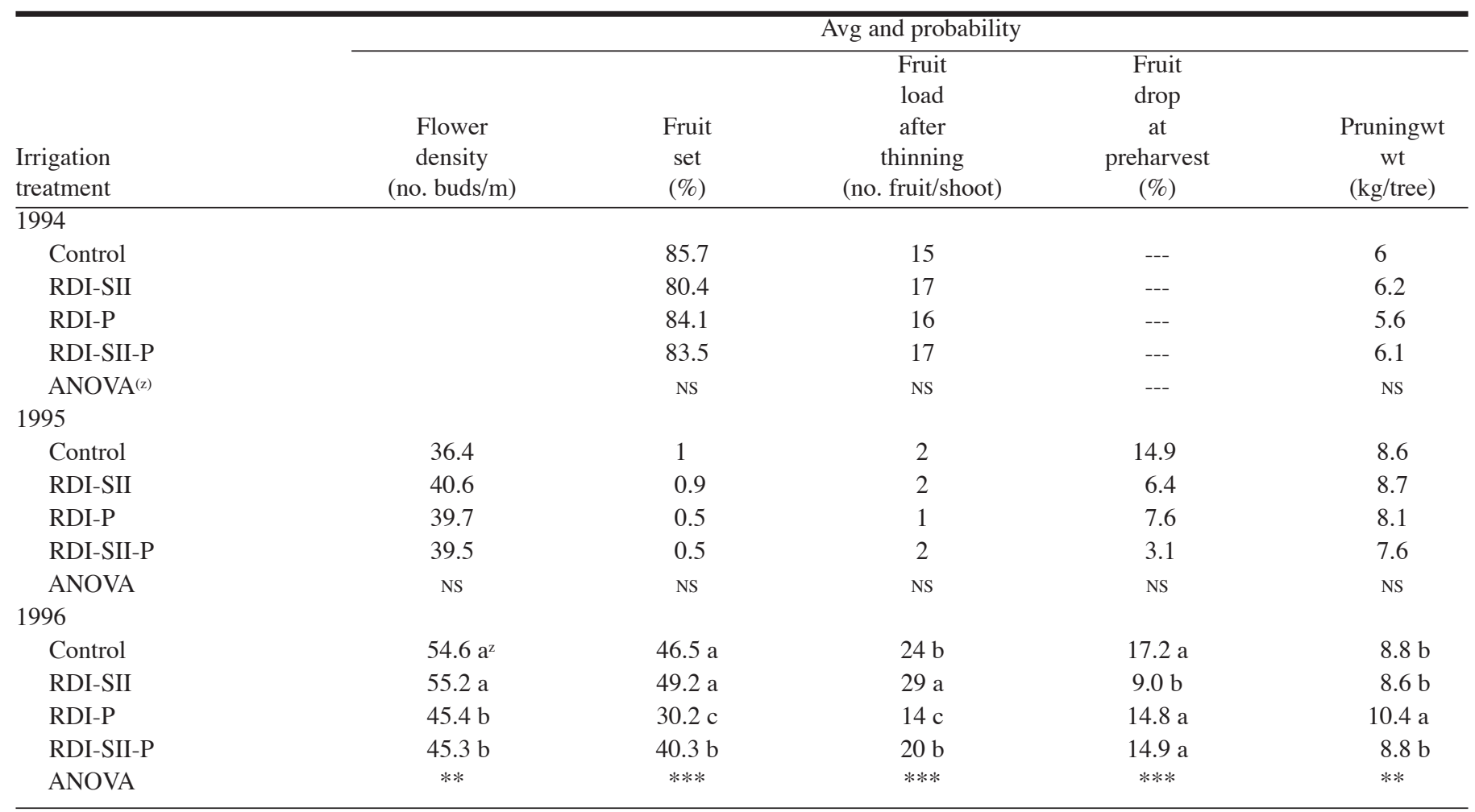

zMeans within column/year followed by different letters were significantly different at $P=0.05$ using Duncan's test. ss,*,******NNonsignificant or significant at $P<0.05,0.01$, or 0.001 , respectively, by ANOVA with complete randomized blocks. 
Table 7. The effect of irrigation treatments during the third year experiment (1996) on crop light interception, proportion of flower buds and average internode length.

\begin{tabular}{|c|c|c|c|}
\hline $\begin{array}{l}\text { Irrigation } \\
\text { treatment }\end{array}$ & $\begin{array}{c}\text { Crop } \\
\text { light } \\
\text { interception } \\
\text { IPPFD }^{(z)} \\
(\%)\end{array}$ & $\begin{array}{c}\text { Flower } \\
\text { buds/ } \\
100 \text { nodes } \\
\text { at } \\
\text { blooming }\end{array}$ & $\begin{array}{c}\text { Avg } \\
\text { shoot } \\
\text { internode } \\
\text { length } \\
\text { (mm) }\end{array}$ \\
\hline Control & $74 a b^{(y)}$ & $107 \mathrm{ab}$ & 5.18 \\
\hline RDI-SII & $70 \mathrm{~b}$ & $109 \mathrm{a}$ & 5.22 \\
\hline RDI-P & $78 \mathrm{a}$ & $93 \mathrm{~b}$ & 5.11 \\
\hline RDI-SII-P & $72 \mathrm{ab}$ & $94 \mathrm{~b}$ & 5.16 \\
\hline ANOVA $^{(x)}$ & * & * & NS \\
\hline
\end{tabular}

${ }^{2}$ IPPFD $=$ intercepted photosynthetic photon flux density.

yMeans within column/year followed by different letters were significantly different at $P=0.05$ using Duncan's test (SAS institute, 1988)

ns, $, * * *, * * *$ Nonsignificant or significant at $P<0.05,0.01$, or 0.001 , respectively, by ANOVA with complete randomized blocks.

could not be the explanation since they were not different (Table 6 ). These differences in fruit count are presumed to have resulted from preharvest fruit drop, because visually more fruit was spread on the orchard floor below the control trees at harvest. A similar observation has been reported for fully irrigated peach trees by $\mathrm{Li}$ et al. (1989). Unfortunately, fallen fruit were not counted before harvest in 1994, but when they were counted in 1996 the treatment differences were apparent, and fruit drop was least in the single deficit treatment during Stage II (RDI-SII, Table 6).

The frost in Spring 1995 did not allow detection of any carry-over effects from RDI treatments on yield behavior, because fruit set was greatly reduced. However, flower density was determined and it was not affected that year (Table 6). The seasonal patterns of the small amount of fruit left on the trees did not clearly manifest a lag phase; this emphasizes the extent to which Stage II is sink limited (Pavel and DeJong, 1993) (Fig 3E). Despite the fact that applied water was reduced to $80 \%$ of the potential consumption because high fruit load is considered a sensitizing factor of the tree to water stress (Berman and DeJong, 1997; Marsal and Girona 1997; Naor et al. 1999), $\Psi_{1}$ values in 1995 tended to be higher than in 1994, whereas $\Psi_{\mathrm{pd}}$ during Stage III indicated the general reductions in

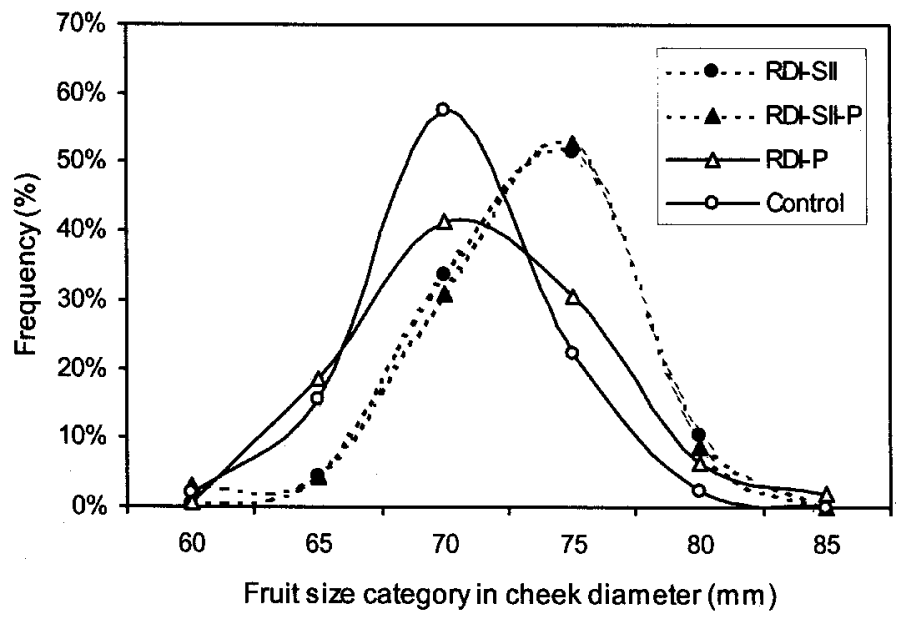

Fig. 4. Distribution of the fruit size categories in 1995 referred to cheek diameter in response to the effects of the irrigation treatments. Each observation corresponds to a treatment average. Open circles with a solid line represent control, closed circles and dotted lines RDI-SII, open triangles and a solid line RDI-P, and closed triangles and a dotted line RDI-SII-P. irrigation for all the treatments (Table 3). The highest values in $\Psi_{1}$ during Stage III were detected in 1996 when there was the lowest evaporative demand (Table 1 and Table 3 ).

In spite of the frost in 1995, more kilograms of fruit were harvested in RDI-SII than in the RDI-P, probably due to a combined effect of higher fruit counts and fruit size which were, however, not statistically significant components by themselves (Table 5). In general, treatments that suffered water stress during Stage II (RDISII-P and RDI-P) had more fruit in higher size categories than those with full irrigation throughout Stage II (control and RDI-P) (Fig. 4). This could relate to a possible fruit growth enhancement after removal of water stress in the RDI trees (Chalmers et al., 1981; Li et al., 1989). However, such a response was not apparent from fruit growth analysis, possibly because of the limited sample size. In 1996, fruit loads were different between treatments so similar comparisons could not be made (Fig. 3F and I).

Carry-over effects were clearly more visible in 1996; flower density and fruit set were significantly reduced in the postharvest deficit treatments (RDI-SII-P and RDI-P) (Table 6). Such a decrease in flower density was not provoked by a shortening of shoot internode length in RDI treatments but by a lower proportion of flower buds per node (Table 7). This could indicate a negative effect on bud differentiation, depending on the time in the annual cycle when water stress occurred (Stage II against postharvest). Irrigation effects on fruit set were even clearer than those on flower density (Table 6). RDI-P trees that manifested more negative $\Psi_{1}$ values than the RDI-SII-P trees during postharvest (Table 3) also had the lowest fruit sets (Table 6). The severity of the water stress levels reached during postharvest, above all in RDI-P, could have been related to a depletion in the carbon reservoir pool and, as a consequence, to a reduction in the sugar content of pistils during the third consecutive spring. A low sugar content in pistils has been related to the speed of pollen tube development and thus to the success of fertilization (Arbeola and Herrero, 1987). Similar results with regard to flowering behavior have been described in almond by Goldhamer and Viveros (2000). They reported that the degree of water deficit before harvest, obtained by progressively increasing the elapsed times of withholding irrigation, was positively related to flower density and fruit set, whereas stress intensity after harvest was correlated to a decrease in both parameters. Lamp et al. (2001) reported that stresses occurring during flower development reduce next season's crop yield because of a reduced flower quality. Although the effects of water stress on

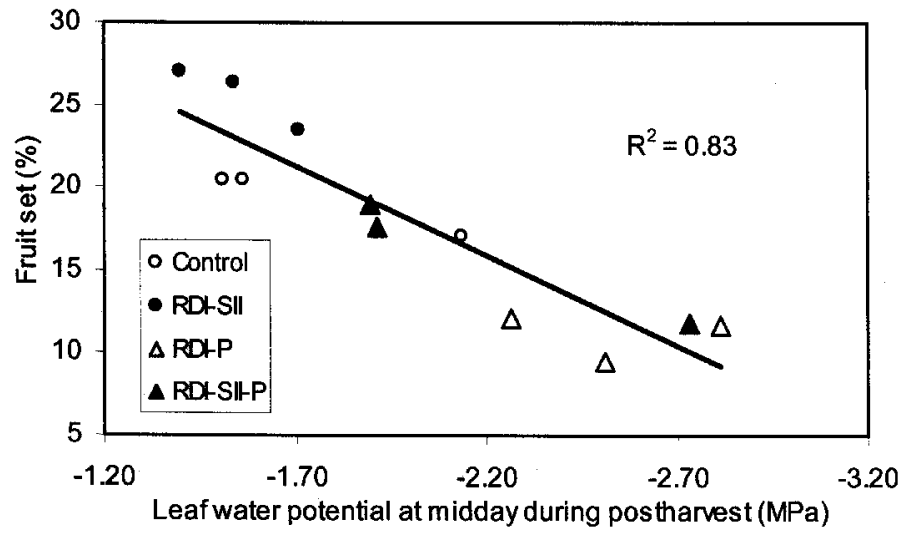

Fig. 5. Relationship between fruit set 2 months after full bloom in 1996 and seasonal average midday leaf water potential during a previous year at postharvest. Each observation corresponds to a treatment average. Open circles control, closed circles RDI-SII, open triangles RDI-P, and closed triangles RDI-SII-P. 
fruit set (FSA1M) and bloom density are identified in Table 6, the relationship of fruit set 2 months after full bloom (FSA2M) versus $\Psi_{1}$ at postharvest clearly shows a decrease in fruit set with $\Psi_{1}$ (from a previous year) becoming more negative (Fig. 5). This response supports the findings reported by Goldhamer and Viveros (2000) and Lamp et al. (2001).

The treatment differences in flower and fruitlet counts in the early spring of 1996 remained after fruit thinning; RDI-P maintained lower counts, whereas RDI-SII again showed the highest values (Table 6). From fruit thinning until harvest, differences in fruit counts between control and RDI-SII-P were not significant, but treatment differences in fruit counts at harvest confirmed the reproductive enhancement in RDI-SII and the negative impact in RDI-P with respect to the control (Table 5). Fruit growth in 1996 was highly influenced by the cropping level, and the tendencies of fresh and dry weight accumulation were highly consistent with a fruit competition effect (Fig. 3G, H, and I). At harvest, average fruit fresh weight was proportional to the fruit load manifested in each treatment and water stress during Stage II did not play a significant role by itself (Table 5). Therefore, the major effects of RDI in this study were related to changes in cropping behavior, which in turn have been fully dependent on the moment when water stress occurred. If water stress was applied during spring (May and early June) or during the shoot growth phase, the trend was to increase the number of fruit and to reduce the final fruit size; whereas if water stress was applied from late summer onward (late August and early September were the moments of maximum water stress) or just after shoot growth cessation, the effect was to reduce fruit load [lower flower density and fruit set (Table 6)] and increase fruit size. Such a bimodal effect highlights the role of irrigation as an important tool for establishing productive targets depending on market preferences. Furthermore, the option to apply a combined RDI treatment (RDI-SII-P) represents an intermediate cropping effect between both extremes and can lead to results similar to those of control. More importantly, RDI-SII-P was the best of the planned irrigation strategies in reducing applied water.

Vegetative growth, and more specifically elongative shoot growth, was clearly reduced in 1994 during Stage II in deficit irrigated treatments (RDI-SII and RDI-SII-P) (Fig. 2A), but this was only evident at the end of this deficit period when the maximum water stress levels were reached (Fig. 2A). The same results were not found during the following experimental years, probably because water deficit can substantially affect the pattern of branching (Hipps et al., 1995). Therefore, a balanced sample size of shoots in trees with different branching patterns may not be enough to evaluate differences of whole tree changes in shoot length (Fig. 2B and C), because shoot number is also an important factor to consider. This is not the case when measuring trunk growth and the increase in TCSA has been shown to be reduced consistently during the first 2-year experiment for the single RDI treatments, and even in a more accentuated fashion in the combined RDI treatment (RDI-SII-P) in accordance with the rate of accumulated water stress during the growth cycle (Fig. 1). These patterns were completely modified in 1996 as a result of the differences in fruit sink strength among treatments; RDI-P experienced the highest growth rates whereas RDI-SII the lowest (Fig. 1). This response in 1996 reflects the importance of fruit load as a vegetative growth regulator, which in this case appeared to be stronger than the drought effects that had occurred over the previous 2 years' irrigation treatments (Fig. 1). At the end of the experiment, the treatment averages of intercepted crop radiation (IPPFD) were arranged inverse to the fruit load estimates in 1996, with the highest and lowest values corresponding to the RDI-P and RDI-SII, respectively (Table 7). In addition, the RDI-P trees visually had more suckers during the summer, which led to the most wood removal during winter pruning (Table 6). In summary, the combined RDI treatment (RDI-SII-P) presented the best opportunities to reduce vegetative growth during the early years; once flowering and fruit load were affected, vegetative control was superior in RDI-SII, whereas the single postharvest treatment (RDI-P) through its reductions in fruit load enhanced vegetative growth.

On the other hand, a yield decrease in a long-term RDI-SII-P strategy cannot be ruled out, because presumably, in 1996, fruit load levels after thinning the control were not different from those of RDI-SII-P(Table 6), but accumulated fruit dry weight was lower in RDI-SII-P than in control, thus losing all the previous advantages gained during Stage I and part of Stage II (Fig. 3H). This loss of fruit growth could be related to reservoir depletion in RDI-SII-P, which in long-term deficit irrigation practices apparently can happen (Esparza et al., 2001). The insertion of a full irrigation year for each 3 years of RDI could tend to minimize the impacts on the reservoir pool and guarantee the long-term results of the combined RDI strategy. When drawing conclusions from this study, one should take the specific crop techniques used in this commercial orchard into account; fruit thinning was minimal to favor high fruit numbers which are recommended in production for canning. Additionally thinning was carried out relatively late on the season (late May, early June). These conditions are very favorable for maintaining the influences of the initial differences on fruit load and also for manifesting their impact on crop yield more effectively.

When comparing the combination of deficit irrigation during Stage II and postharvest (RDI-SII-P) to fully irrigated trees (control), final fruit size, number, and yield were not affected, while a more favorable fruit to vegetative growth balance and the highest water saving (22\%) was achieved. The level of water savings during postharvest almost doubled that of Stage II, which makes postharvest a more appealing period than Stage II for saving applied water.

In conclusion, for late maturing peach trees in shallow soils RDI-SII reduced fruit drop and improved final fruit set compared to control. Water stress imposed in postharvest clearly reduced flower density and fruit set in 1996. Short term and long term vegetative effects on RDI in peaches could be acting in different ways: in the short term (year 1994) RDI reduced vegetative growth according to the experienced water stress, while in the long term (year 1996, after 3 years of applying the same irrigation treatments) the effects on vegetative growth were mediated by crop load. An excessive water stress applied during postharvest can unexpectedly enhance tree vigor if crop load is substantially reduced in the following years. For practical implications, postharvest water stress should be managed carefully in order to avoid reductions in bloom return and fruit load, especially on shallow soils. The management of water stress during stage II is less critical, and may have the benefits of controlling vegetative growth, increasing flower density and commercial fruit load.

\section{Literature Cited}

Alegre, S., J. Marsal, M.J. Tovar, M. Mata, A. Arbonés, and J. Girona. 2002. Regulated deficit irrigation in olive trees (Olea europaea L. cv. Arbequina) for oil production. Acta Hort. 586:259-262

Arbeola, A. and M. Herrero. 1987. The significance of the obturator in the control of pollen tube entry into the ovary in peach (Prunus persica). Ann. Bot. 60:681-685.

Behboudian, M.H. and T.M. Mills. 1997. Deficit irrigation in deciduous 
orchards. Hort. Rev. 21:105-131.

Berman, M.E. and T.M. DeJong. 1997. Crop load and water stress effects on daily stem growth in peach (Prunus persica). Tree Physiol. 17:467-472.

Boland, A.M., P.H. Jerie, P.D. Mitchell, I. Goodwin, and D.J. Connor. 2000. Long-term effects of restricted root volume and regulated deficit irrigation on peach: II. Productivity and water use. J. Amer. Soc. Hort. Sci. 125:143-148.

Boland, A.M., P.D. Mitchell, and P.H. Jerie. 1993. Effect of saline water combined with two restricted irrigation on peach tree growth and water use. Austral. J. Agr. Res. 44:799-816.

Caspari, H.W., M.H. Behboudian, and D.J. Chalmers. 1994. Water use, growth, and fruit yield of 'Hosui' asian pears under deficit irrigation. J. Amer. Soc. Hort. Sci. 119:383-388.

Chalmers, D.J., P.D. Mitchell, and L. van Heek. 1981. Control of peach growth and productivity by regulated water supply, tree density and summer pruning. J. Amer. Soc. Hort. Sci. 106:307-312.

Chalmers, D.J., K.A. Olsson, and T.R. Jones. 1983. Water relations of peach trees and orchards, p. 197-232. In: T.T Kozlowski (ed.). Water deficits and plant growth. vol 6. Academic Press, London.

Crisosto, C.H., R.S. Johnson, J.G. Luza, and G.M. Crisosto. 1994. Irrigation regimes affect fruit soluble solids concentration and rate of water loss of 'O' Henry' Peaches. HortScience 29:1169-1171.

DeJong, T.M. 1995. Orígenes del riego deficitario controlado (RDC) y su importancia actual en el manejo e investigación del riego. Seminario Internacional El gran debate del agua. II Simposio sobre riego y eficiencia en el uso del agua. Lleida (Spain) 1995:19-20.

Domingo, R., M.C. Ruiz-Sánchez, M.J. Sánchez-Blanco, and A. Torrecillas. 1996. Water relations, growth and yield of Fino lemon trees under regulated deficit irrigation. Irrig. Sci. 16:115-123.

Doorenbos, J. and W.O. Pruitt. 1977. Crop water requirements. Irr. Drainage Paper. FAO, Rome, Italy.

Esparza, G., T.M. DeJong, and S.A. Weinbaum. 2001. Effects of irrigation deprivation during the harvest period on nonstructural carbohydrates and nitrogen contents of dormant, mature almond trees. Tree Physiol. 21:1081-1086.

Fereres, E. and D.A. Goldhamer. 1990. Deciduous fruit and nut trees. In: B.A. Stewart and D.R. Nielsen (eds.). Irrigation of agricultural crops. Amer. Soc. Agron. (Madison, Wis.) Monogr. 30:987-1017.

Generalitat de Catalunya. 1994. PAC-COM. Version 2.00 (manual reference). Survey Center of Xarxa Agrometerològica de Catalunya.

Girona, J. 1989. Physiological, growth and production responses of late maturing peach (Prunus persica $\mathrm{L}$. Batsch) to controlled deficit irrigation. MS thesis. Univ. Calif., Davis.

Girona, J., J. Marsal, M. Mata, A. Arbonés, and C. Miravete. 1997. Evaluation of almond (Prunus amygdalus L) seasonal sensitivity to water stress. Physiological and yield responses. Acta Hort. 449(2): 489-496.

Girona, J., M. Mata, D.A. Goldhamer, R.S. Johnson, and T.M. DeJong. 1993. Patterns of soil and tree water status and leaf functioning during regulated deficit irrigation scheduling in peach. J. Amer. Soc. Hort. Sci. 118:580-586.

Goldhamer, D.A. 1999. Regulated deficit irrigation for California canning olives. Acta Hort. 474:369-372.

Goldhamer, D. and R.L. Snyder. 1989. Irrigation scheduling: A guide for efficient on-farm water management. Univ. Calif. Div. Agr. Nat. Res. Publ. 21454.

Goldhamer D.A. and M. Viveros. 2000. Effects of preharvest irrigation cutoff durations and postharvest water deprivation on almond tree performance. Irr. Sci. 19:125-131.

Goldhamer, D.A., E. Fereres, M. Mata, J. Girona, and M. Cohen. 1999. Sensitivity of continuous and discrete plant and soil water status monitoring in peach trees subjected to deficit irrigation. J. Amer. Soc. Hort. Sci. 124: 437-444.

Gonzalez-Altozano, P. and J.R. Castel. 1999. Regulated deficit irrigation in "Clementine Nules" citrus trees. I. Yield and fruit quality effects. J. Hort. Sci. Biotech. 74:706-713.

Hipps, N.A., L. Pagès, J.G. Huguet, and V. Serra. 1995. Influence of controlled water supply on shoot and root development of young peach trees. Tree Physiol. 15:95-103.

Johnson, R.S., D.F. Handley, and T.M. DeJong. 1992. Long-term response of early maturing peach trees to postharvest water deficits. J. Amer. Soc. Hort. Sci. 117:881-886.

Lamp, B.M., J.H. Conell, R.A. Duncan, M. Viveros, and V. Polito. 2001. Almond flower development, floral initiation and organogenesis. J. Amer. Soc. Hort. Sci. 126:689-696.

Lampinen, B.D., K.A. Shackel, S.M. Southwick, B. Olson, J.T. Yeager, and D.A. Goldhamer. 1995. Sensitivity of yield and fruit quality of French prune to water deprivation at different fruit growth stages. J. Amer. Soc. Hort. Sci. 120:139-147.

Li, S.H., J.G. Huguet, P.G. Schoch, and P. Orlando. 1989. Responses of peach tree growth and cropping to soil water deficit at various phenological stages of fruit development. J. Hort. Sci. 64:541-552.

Marsal, J. and J.Girona. 1997. Relationship between leaf water potential and gas exchange activity at different phenological stages and fruit loads in peach trees. J. Amer. Soc. Hort. Sci. 122(3):415-421.

Marsal, J., H.F. Rapoport, T. Manrique, and J. Girona. 2000. Pear fruit growth under regulated deficit irrigation in container-grown trees. Scientia Hort. 85:243-259.

Marsal, J., M. Mata, A. Arbones, J. Rufat, and J. Girona. 2002. Regulated deficit irrigation and rectification scheduling in young pear trees: an evaluation based on vegetative and productive response. Eur. J. Agron. 17:111-122.

Mitchell, P.D., P.H. Jerie, and D.J. Chalmers. 1984. The effects of regulated water deficits on pear tree growth, fruit growth and yield. J. Amer. Soc. Hort. Sci. 109:604-606.

Naor, A., I. Klein, H. Ruppert, Y. Grinblat, M. Peres, and A. Kaufman. 1999. Water stress and crop level interactions in relation to nectarine yield, fruit size distribution and water potentials. J. Amer. Soc. Hort. Sci. 124:189-193.

Pavel, E.W. and T.M. DeJong. 1993. Source- and sink-limited growth periods of developing peach fruit indicated by relative growth analysis. J. Amer. Soc. Hort. Sci. 118:820-824.

SAS Institute. 1988. SAS/STAT user's guide. Release 6.03 ed. SAS Inst., Cary, N.C.

Scholander, P., H. Hammel, E. Bradstreet, and E. Hemmingsen. 1965. Sap pressure in vascular plants. Science 148:339-345.

Turner, N.C. and M.J. Long. 1980. Errors arising from rapid water loss in the measurement of leaf water potential by the pressure chamber technique. Austral. J. Plant Physiol. 7:527-537. 